Article

\title{
Assessment of the Bus Transit Network: A Perspective from the Daily Activity-Travel Organization of Travelers
}

\author{
Marc-Edouard Schultheiss
}

check for updates

Citation: Schultheiss, M.-E

Assessment of the Bus Transit

Network: A Perspective from the

Daily Activity-Travel Organization of

Travelers. Sustainability 2022, 14, 2406

https://doi.org/10.3390/su14042406

Academic Editor: E. Owen

D. Waygood

Received: 20 January 2022

Accepted: 16 February 2022

Published: 19 February 2022

Publisher's Note: MDPI stays neutral with regard to jurisdictional claims in published maps and institutional affiliations.

Copyright: (C) 2022 by the author. Licensee MDPI, Basel, Switzerland. This article is an open access article distributed under the terms and conditions of the Creative Commons Attribution (CC BY) license (https:// creativecommons.org/licenses/by/ $4.0 /)$.
Laboratory of Urban Sociology, École Polytechnique Fédérale de Lausanne, 1015 Lausanne, Switzerland; marc-edouard.schultheiss@epfl.ch

\begin{abstract}
In a context where daily car use is a spontaneous and habitual choice for a wide majority of the population, the quality of the alternatives to individual motorized vehicles is a major factor in encouraging modal shift. The ease of access to public transport can influence the mode choice decision process. However, the diversity of activity-travel patterns questions the definition of a unique and homogeneous accessibility and level-of-service to all travelers. The aim of this paper is to identify, with the help of standard data (micro-census and open data), for whom, when and where the transit supply is adequate or not. The approach is based on a twofold methodology. First, we aim to identify differentiated typical activity-travel patterns among the population. Second, to decompose them in transit supply in time and space. Combined, these two elements synthesize a spatially- and temporally-based demand-supply gap index. The results show for which territories, time slots and population groups the supply is defective or excessive with respect to the demand. Generally speaking, the supply is particularly well dimensioned for the dominant groups, such as commuters, including long-distance travelers, who are mainly men. The imbalances in supply over time and space reveal a differentiated accessibility but also significant socio-spatial inequalities.
\end{abstract}

Keywords: public transport; demand-supply gaps; temporal analysis; spatial analysis; activity-travel pattern

\section{Introduction}

This project proposes pragmatic avenues for better understanding where, when and for whom the public transport network is or is not accommodating. The National Association of City Transportation Officials [1] explains that "much of the transit street design challenge lies in aligning the priorities and demands of city departments with those of transit operators, and in demonstrating the value of investments and dedicated street space to city residents and leaders". This quote helps setting the context of urban transit, that involves multiple stakeholders, politics, tax-payers' money, private operators and public space. In the context of Europe, despite a clear commitment to promote a modal shift in cities-and, in particular, the use of public transport-modal shares have remained stable overall for the past fifteen years. Cities remain predominantly occupied by cars. Public transport remains largely overlooked. While cars have great qualities for individuals (flexibility, safety, comfort), they remain incredibly inefficient in terms of the use of urban space (low passenger volume per hour at road capacity, dedicated parking space, congestion). At the same time, the transit system is designed primarily to get people to work [2] (p. 10), and the system's capacity is generally sized based on aggregated daily passenger volumes. This trip-based planning approach exacerbates the peak hour effect, by concentrating the transit supply in narrow time slots, and by connecting the major points of interest in a city. Yet, activity-chaining is barely considered, and insufficient effort is made to allow people to build their lives around the public transit system, and in particular regarding bus transit [2] (p. 24).

The transit network connects places to live, work and play (e.g., amenities, services, jobs), and the impact of the public transport system is manifold. It influences the economic context (e.g., housing market, job accessibility), can cause new forms of residential 
appropriation (e.g., gentrification, social housing) and can transform the social-scape of entire neighborhoods (as suggested in the research about Janes Jacob's urban vitality and transit ridership by Sulis et al. [3]). Mezoued and colleagues [4,5]—in their work about city dynamics, new proximities and the slow metropolis-discuss the importance of permeability and walkability in the sustainable developments of mobility infrastructures, often driven by functional, political or economic logics. To synthesize his idea of a qualitative transit network, the authors develop the "transit adherence". Adherence encompasses a spatial component, questioning how porous the infrastructures are with respect to the neighborhoods, how walkable are the first and last miles to connect the service to the departure or arrival location. It encompasses a governance component, questioning how committed are deciders to engage with the population, what place is given to public transit on the streets, how subsidized it is, but also what are the ridership and coverage strategies to provide a fast and frequent supply. Lastly, transit adherence encompasses the diversity of travelers: integrating the practices, usage and attitudes of the communities also appears critical for transit attractiveness.

Are we all equal when it comes to the quality of the public transport supply? Do we all have the same freedom of choice and opportunity of accessibility? What happens on the fringe of the main places of interest, and around the peak hours that structure the rhythm of cities? And who is left out?

If public transit is allegedly very good at connecting amenities, employment areas and recreation sites, this research questions whether public transit remains qualitative with respect to the diversity of activity-travel patterns. This research aims to dig beneath what a daily picture of human activity and movement can show, in terms of major points of interest and peak hours. It compares the needs of the population (activity-travel demand) with the capacity of the public transport network (public transport offer). The objective is to propose a method to evaluate how accommodating the public transit network is in its spatial and temporal dimensions with respect to people's organization. This method is purposely based on standard data formats. The approach aims at segmenting the population into six typical activity-travel behaviors, the territory into four types, and the day into five time slots. These three dimensions are then cross-referenced and analyzed to assess the performance of the public transit network with respect to the demand. The results indicate time slots, territories and populations for which the public transport supply is overestimated or underestimated.

The rest of the paper is organized as follows. Section 2 reviews what makes the quality of transit supply, and how the activity-travel demand is characterized in the field. Section 3 presents the general framework, material and use case of the research. This includes the description of the data (mainly travel surveys and public transport schedule open-data), and the different data sources are processed, matched and combined to yield a public transport capacity index. Section 4 presents the results that differentiate temporal, spatial and organizational layers in the public transport capacity assessment. Lastly, Section 5 and 6 discuss the results, suggest an avenue for rebalancing the public transport supply across temporalities, territories and typical activity-travel patterns, and provide the concluding remarks.

\section{Literature Review}

Public transit assessment traditionally belongs to the practice of transportation engineers, which results in very functional criteria. In this section, the factors for assessing the quality of the public transit supply are reviewed from a wider perspective, including urban sociology and, broadly, city sciences. Similarly, the demand for movement is introduced as heterogeneous in terms of activity-travel needs. The diversity of patterns allows us to move beyond the socio-economic approach that gives prime importance to income, gender or education to understand mobility practices. Lastly, existing works that contrast travel demand and public transport supply are described. 


\subsection{Factors for Assessing the Quality of the Public Transport Offer}

Generally focused on commercial speed and operating costs, the assessment (mostly engineer-driven) of the quality of the public transit is undervalued. In practice, the transit network is often designed to get transit-dependent people to their job. Since very recently, however, cities around Western Europe (and probably beyond) are shifting their transit development strategies to integrate discretionary travelers (people who have a viable modal alternative) and multiple trip purposes. On public transit encouragement, the Transportation Demand Management Online Encyclopedia [6] explains that discretionary transit riders find transit travels less stressful than with a car, and more convenient for some trips. They want to be able to access transit service within a walkable distance and a reliable, well-connected and fast service. Understanding what car users like or expect from the public transit service is key to developing strategies to increase ridership. In this direction, Hale [7] stresses that "transport is changing, so assessment must change", and identifies seven categories of metrics to guide public transit assessment. These metrics are established on various scales (from metropolitan to neighborhood) and range from land-use, to system-related or accessibility indicators. Geurs and ven Wee [8] provide an in-depth review of accessibility and stress that a typical evaluation of transport strategies do not satisfy theories, which call for a feedback mechanism between the land-use, the transport system, the temporal and the individual components. Below, this four-component approach is used to report and classify what the extensive literature says about the quality of public transit (including works of [9-14] and many others):

- Land-use component traditionally refers to the job areas, population densities and major amenities and services of a city. More generally, it refers to the locations and characteristics of opportunities in a city to live, work and play. Yet, it should not only be about connecting major points of interest. It must also enable compact or quarter cities, geographic equity, complete streets, transit-oriented developments, walkability and mixed-use in the vicinity of the transit infrastructures.

- Transport system component refers to the ease of using the transit service and obtaining information. It refers to the comfort, affordability and overall effectiveness and convenience (availability, reliability, frequency, commercial speed and headways). Some experts also mention the aesthetics of vehicles, stops, transfer areas or even the subscription documents or cards.

- Temporal component reflects the coupling and authority constraints as described in Time-Geography, that shape people's activity-travel schedule and organization. More broadly, considering the temporal component allows one to account for activity chaining and time-allocation; and to let travelers build their lives around transit.

- Individual component refers to the needs, abilities and opportunities of individuals, as well as the individual's time-space constraints. In practice, individuals are considered from a socio-economic perspective, including income, gender, education. Moreover, the field of psychosociology refers to the social constructs related to transit and the low social status easily associated to transit riders.

Without being necessarily exhaustive, the assessment of the transit network must therefore encompass social, spatial and temporal components in addition to the transport system characteristics.

\subsection{A Heterogeneous Demand in Time and Space with Differentiated Activity-Travel Patterns}

The conceptual model of travel behavior proposed by van Acker, van Wee and Wiltox [15] (p. 219) "considers travel behavior as derived from locational behavior and activity behavior". People develop activity and locational preferences or habits, and tend to stick with them for some time, as this is the result of a long, iterative and hierarchical decision-making process. Consequently, this framework suggests that certain patterns of activity and travel could be used to characterize an individual's mobility behavior. Besides, as argued by the authors [15] (p. 227), socioeconomically homogeneous population segments behave differently, as attitudes and preferences lead to rather unreasoned behaviors. 
This questions the traditional socioeconomic and utilitarian approach to plan and forecast travel behaviors.

Recent research proposes promising alternatives. For example, the application of activityor location-based mobility motifs to travel behaviors [16] unveiled a limited set of a very distinctive activity-travel graph. Depending on the nature of the data (call detail records, GPS, travel surveys) and the definition of the motif (location- or activity-based), motif-related research shows between 10 and 17 motifs that can capture $90 \%$ of the population activity-travels. These motifs also show spatio-temporal regularity and stability over several months [16-20]. This tends to confirm that typical locational and activity patterns exist and can be leveraged to capture a greater diversity of activity-travel behaviors.

Another approach worth mentioning is the data-driven classification of the activitytravel behaviors. Reades et al. [21] focus on territories and propose a spatial typology based on volumes of visitors at different times of the day. The idea is to classify locations with respect to their temporal occupation profile. This has a clear application for transit planning, but lacks a "social" component, as it is solely based on volumes of visitors. Ahas et al. [22] focus on time and were interested in understanding the locational and temporal diurnal rhythms of suburban travelers. Their results display clear locational patterns and scheduling strategies, which served to define a temporal typology of suburban travel demand. The same approach could be used for urban and exurban populations to better fit the transit supply, or any public service opening hours.

Lastly, other researches propose a method to cluster individuals based on their activity diary, characterized in terms of location, time and duration of activities. Shen and Cheng [23] extracted and classified individual space-time activity profiles based on the detection of time-stamped points-of-interests. They obtained four clusters with similar time-space patterns. Drevon and Gumy [24] developed a similar idea, while giving due importance to the dwelling in the activity-travel patterns, including variables such as the maximum distance from home or the count of home-loops. They came up with 10 profiles that account for the complexity of activity-travel organization, the temporal constraint and the time-space dispersion over a typical day.

\subsection{Existing Works That Contrast Travel Demand and Public Transport Supply}

A cursory analysis of the transit ridership at the metropolitan scale reveals a fairly capacitated network. The bimodal curves characteristic of supply (number of vehicles or seat capacity in operation) and demand (number of travelers departing) show very similar trends, with two peaks (morning and evening) connected by a plateau. However, some research studying supply-demand gaps shows different results when supply and/or demand are decomposed. A seminal work by Jiao and Dillivan [25] aims precisely at identifying discrepancies "between level of transit service (supply) and needs of a particular population (demand)" ([25], p. 23). In its definition, the concept refers to areas where the transit-dependent population is not adequately served, which leads to social exclusion and transport poverty [26].

The literature counts many different ways to build an indicator of supply. Most of them are accessibility-based ([27] about public Transport Accessibility Level; [28] about fine-grained accessibility; [29] about Transport Performance Index focused on residents satisfactions and expectations; [30] about a Public Transport Service Accessibility Index). In fact, considering accessibility allows one to account for urban forms (distribution of jobs, population density, etc.) and transportation system characteristics (network density, headways, etc.).

Indicators of demand remain straightforward and are usually measures of trip volumes observed in travel surveys and extended or synthetically generated with job distributions and population densities.

The demand-supply gaps result from the difference between a supply index and a demand index. The wide majority of demand-supply gap analyses are space-based and therefore do not integrate the temporal variations of supply and demand. For example, 
Peungnumsai and colleagues [31] propose a gap analysis between the daily capacity of various public transit modes and daily trip volumes. The results demonstrate great disparities between high- and low-income populations, with a network overly concentrated inward and spatially unbalanced. Similar space-based studies exist and allow for the identification of areas where sociodemographic segments show a discrepancy between demand and supply (e.g., [14,32,33]). Kaeoruean et al. [34] introduced the concept of hourly gaps. This gives a temporal depth to the usual space-based gap analyses. Despite the partial results due to data unavailability (only morning travels), they demonstrate that supplydemand gaps are dynamic. The same area can be undersupplied at time $t$ and oversupplied at time $t+1$. Beyond capacity, and from a supply perspective, the transit system is also dynamic in its commercial speed or comfort. At peak hours, for example, networks reach capacity, people stand while traveling and the average travel time decreases [35]. The urban systems are also dynamic from a demand perspective, as major points-of-interest gain more or less urban vitality at different times of the day [3].

Integrating time in supply-demand assessment is very promising for improving the transit system's efficiency. In practice, lowering the demand at peak hours by altering urban rhythms (e.g., by shifting working schedules) seems to be an effective way to reduce transit congestion. However, research shows that relaxing solely the fixed working schedules does not affect the peak hours travel demand dramatically [36], as other non-work commitments are also a vector of activity-travel fixity [37]. These findings demonstrate a certain urban hegemony of peak hours that needs to be treated with attention.

The literature is quite unanimous on what makes the quality of a public transit system. The spatial dimension and transport characteristics have been extensively documented. In contrast, the temporal and individual components are still poorly studied. The stateof-the-art calls for a space-time-based assessment of supply-demand gaps. Additionally, the needs, abilities and opportunities of individuals, as well as the individuals' time-space constraints, still need to be accounted for.

\section{Materials and Use Case}

As a first intention, this section describes the data used in the project to establish public transport supply and travel demand. Standard travel survey data and open data were purposely chosen for reasons of replicability. Next, the methodological framework describes how supply and demand data were combined to assess the socio-spatial and temporal gaps between supply and demand in the public transportation system. The research case study is the Greater Geneva Area, a cross-border agglomeration of 212 towns. The city of Geneva (Switzerland) constitutes a very attractive center. More than one out of two working people living in the bordering communes (on the French side) actually work in Geneva (on the Swiss side). This economic attraction drains thousands of cross-border workers every day, and the city of Geneva is the most congested city in Switzerland. Workers often come from remote, rural areas barely connected to the public transport network. The stakes for developing an adequate network, in terms of connections to peripheral territories but also adapted schedules, are therefore critical for the city of Geneva.

\subsection{Data Describing the Public Transport Supply}

In recent years, a collective effort has been made to harmonize public transport data. This resulted in the General Transit Feed Specifications (GTFS), a standard that transit agencies use globally to maintain their transit offer specification feed. Real-time feeds allow third parties, in particular, to develop services on top of the operators' schedule, such as seamless ticketing, multi-modal routing or simply real-time and personalized information. The GTFS data are structured in several files containing both timetable and network geometry information about stops, stop times, trips and routes that are all connected via a certain ID [38]. All the specificities of the public transport network and operation are referenced, such as the different agencies, the fare attributes, the specific calendar days, etc. Several libraries flourish online to ease the processing of frequent GTFS spatial analysis and to unlock the potential of such 
global and open data. For example, the GTFS function library [39] groups a series of basic functions to calculate stop or line frequencies, segment speeds as well as geometry operations. The $g t f s p y$ library [40] allows spatial and temporal filtering to focus on a given time slot and a given territory. The peartree library [41] converts the data into a directed network graph that allows for the combination with other network, such as OpenStreetMap. It also allows for centrality analyses, or routing and shortest path analyses.

As detailed in Section 3.2, the travel demand data were collected in 2015-2016. At that time, the Swiss GTFS data were still incomplete. As of 2018, the data were evaluated to be sufficiently well maintained to objectively appraise the supply. Thus, in order to get as close as possible to the travel demand data, the GTFS data from 25 April 2018 (opentransportdata.swiss 2020) are employed. Apart from some schedule and bus line adjustments, no major network changes have been undertaken in the meantime. The time discrepancy is assumed to barely affect the results. The data count 1221 public transport stops, mainly composed of buses for the road network, and trains and trams for the rail network. Three categories of public transport are distinguished, namely the bus, tramway or regional train, and train. The network is rather dense because of the Swiss Guaranteed Ride Home policy, that obliges any town to be connected to the public transit network.

From the Swiss GTFS data, the stops in the Greater Geneva area were extracted. It was also necessary to merge different GTFS databases (merge Python script available upon request), as the research focuses on a cross-border area (France-Switzerland). This preliminary procedure resulted in a consolidated cross-border supply matrix, mapped in Figure 1.

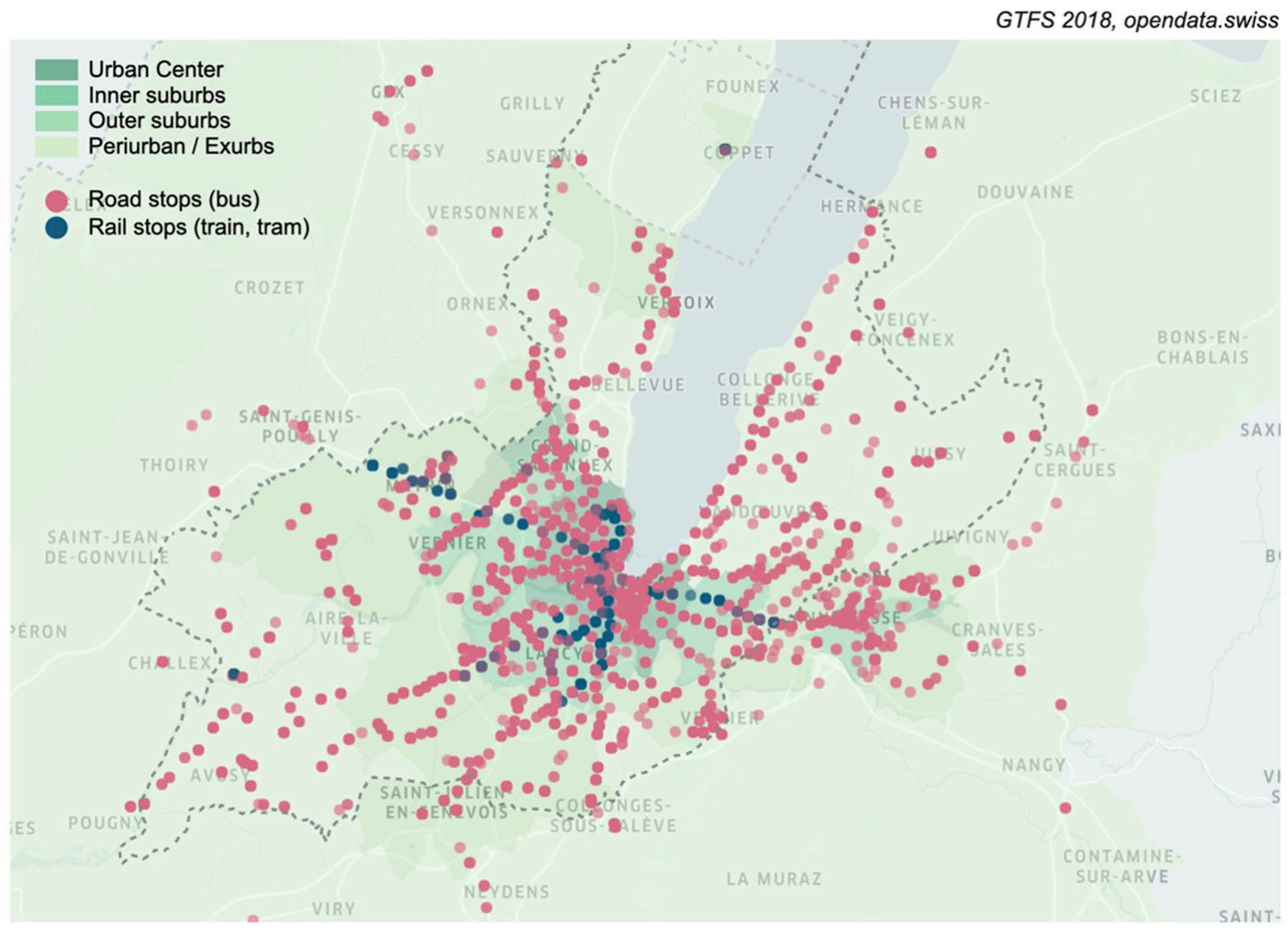

Figure 1. Spatial structure of the public transport offer across the Greater Geneva Area.

Finally, the data are arranged to be consistent with travel survey data. That is, for each minute of a "typical day" ( $t=0$ to $t=1440)$, all vehicle movements are identified in a single data frame, labeled by a mode (bus, transit or train) and contextualized by a route id, an origin and a destination. Moreover, each vehicle movement is associated to a time period (morning peak, off-peak, etc.; further described in Section 4.3); and a territorial typology 
(spatial join operation based on the typology described in Section 4.3) according to the geo-referencing information of the stops and stations of origin of the trip. The volumes of vehicles are presented in Figure 2.
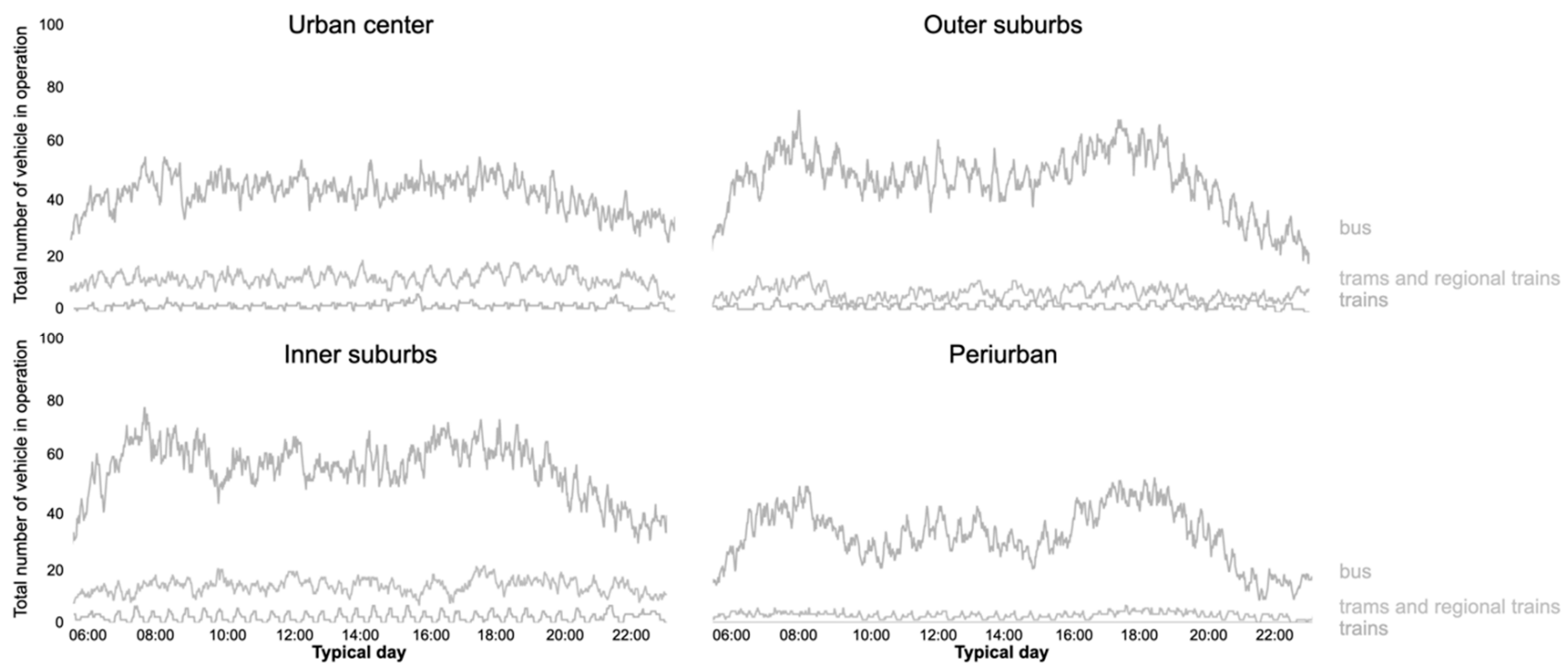

Figure 2. Cumulative sum of the bus, transit and train vehicle count per territory.

\subsection{Data Describing the Activity-Travel Demand}

The second part of this work focuses on travel demand. The data on travel demand is drawn from the Mobility and Transport Microcensus (MTMC, 2015) on the Swiss side, and the Travel Survey Greater Territory (EDGT, 2016) on the French side. Both databases are built on similar methodological principles and allow for the identification of: (a) the place of departure and arrival of each trip; (b) the time of departure and arrival of each trip; (c) the mode of transport used for each trip; and (d) the activity for which the trip is made. Socio-economic characteristics of the individual (gender, age, etc.) are also available. The combined database contains 7427 representative observations, which allow us to work with actual and observed demand. In the literature, demand is usually synthesized from socio-spatial and accessibility information. For example, Peungnumsai and colleagues [31] propose an estimate of travel need with a demand index that combines household travel demand survey, population density and income per Traffic Analysis Zones.

One of the main research questions of this paper is to differentiate mobility needs to capture a greater diversity in activity-travel patterns. Different methods have been reviewed to capture this diversity (see Section 3.2). This research relies on a hierarchical classification, similar to that developed by Drevon and Gumy [24]. This methodology is applied for the first time in a cross-border context. The classification yielded six typical activity-travel patterns. Figure 3 presents the descriptive statistics of some of the explanatory variables used in the determination of the three latent variables that were used as classification inputs. These latent variables are (a) the complexity of the daily activity schedule; (b) the temporal constraints; and (c) the time-space dispersion. 

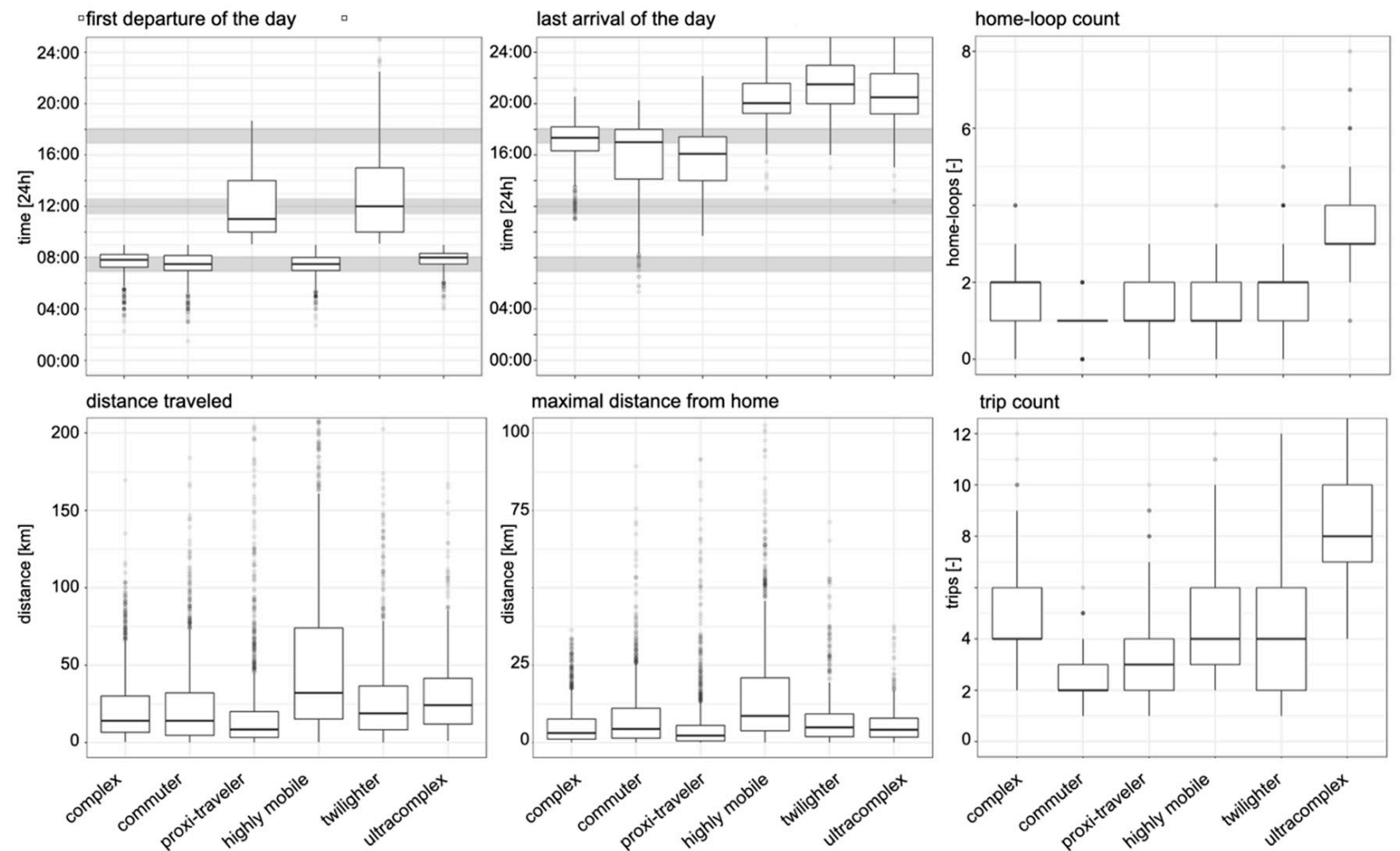

Figure 3. Descriptive statistics of travel demand, the explanatory variables used to determine the activity-travel patterns.

These patterns are purposely established independently of the geographic context, socioeconomic categories and modal preferences. In-depth analyses have shown the emergence of trends-or preferences. For example, the highly mobile pattern concerns mostly men with high incomes, who predominantly use the train for daily travel.

\subsection{Methodological Framework}

With the combination of different datasets and the comparison of quantities in different units (supply is the count vehicle visits at each bus station, and demand is a volume of travelers), the method is an important development in this work. Figure 4 summarizes the different steps undertaken from the raw travel data and GTFS data to the assessment of the public transport network. The upper part of the flow diagram focuses on the demand. After matching the two travel surveys and extracting typical activity-travel patterns as described before, the travel volumes are segmented per time slots and territorial typology. Similar data transformation is done for the transit supply, as described in the lower part of the flow diagram. Thus, the day is decomposed into $1440 \mathrm{~min}$ that fall within 5 time slots, and the territory is split into 5 parts. The rest of the section describes these territorial and temporal splits.

Table 1 summarizes the five time slots selected for this research: morning peak hour (07:00-09:10), off-peak hours, noon, evening peak hours (15:55-19:25) and night. These time slots are determined on the basis of the bus supply, i.e., the number of vehicles in circulation in the network. Namely, the peak hours begin and end when the network passes the threshold of $80 \%$ of its maximum offer in the whole of Greater Geneva (in absolute values, 120 buses in circulation out of a maximum of 150). 


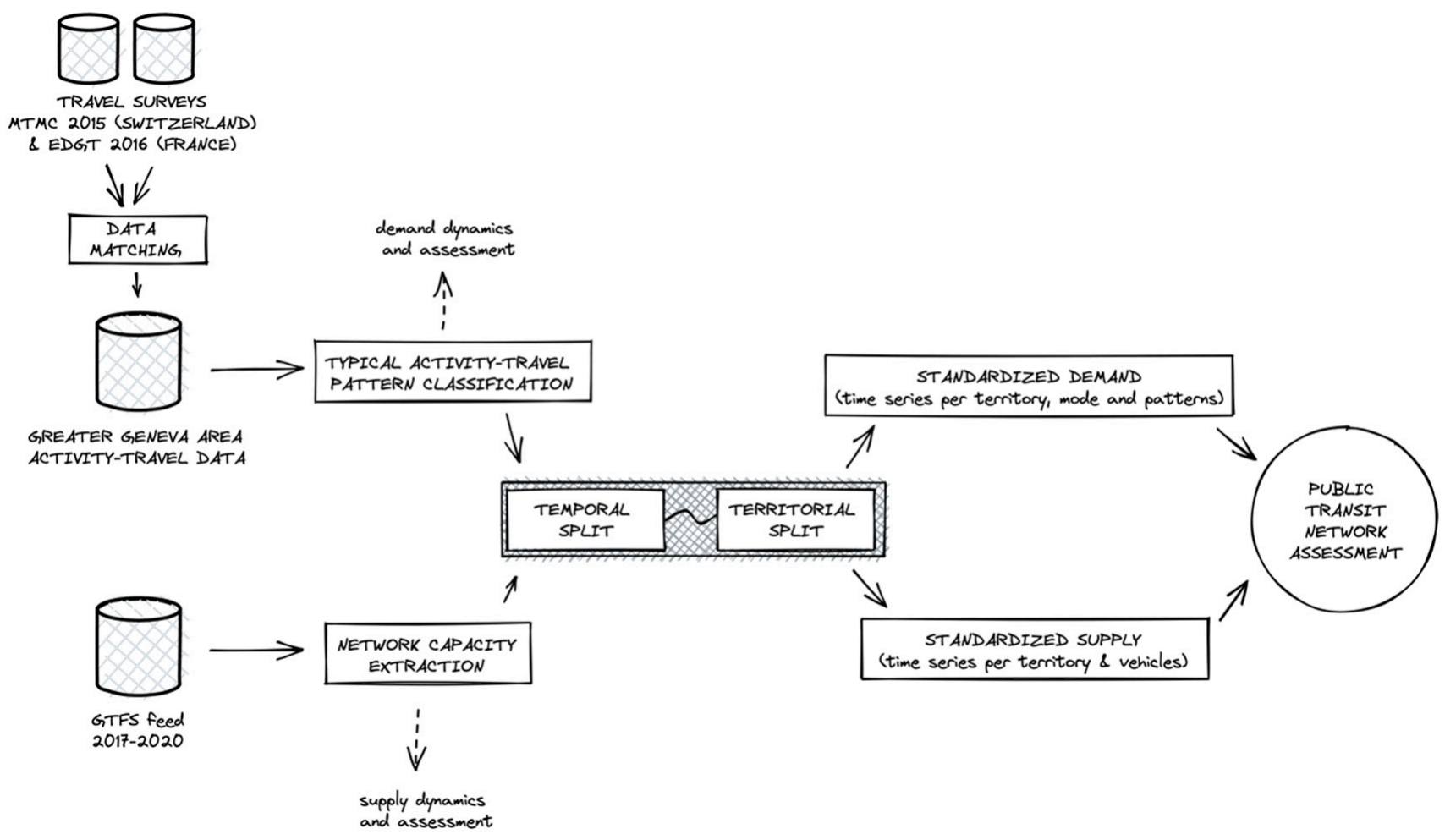

Figure 4. Flow diagram, depicting the general framework from raw data gathering to the assessment of the public transport network capacity.

Table 1. Supply-based peak hours in the Greater Geneva Area.

\begin{tabular}{ccc}
\hline Time Slots & Start & End \\
\hline Day & $00: 00: 01$ & $23: 59: 59$ \\
Morning Peak Hour (MPH) & $07: 00: 00$ & $09: 10: 00$ \\
Off Peak Hour (OPH) & $09: 10: 00$ & $15: 55: 00$ \\
Noon & $12: 00: 00$ & $14: 00: 00$ \\
Evening Peak Hour (EPH) & $15: 55: 00$ & $19: 25: 00$ \\
Night & $19: 25: 00$ & $23: 59: 59$ \\
\hline
\end{tabular}

The adoption of this temporal distribution is supported by additional analyses. The relative vehicle frequency at stop $i$ and time $t$ is used to offset the invariants of daily vehicle frequency during the time slot $\mathrm{t}$ :

$$
\text { Freq } q_{i, t}^{r e l}=\text { Freq }_{i, t}^{a b s} / \text { Freq } q_{i, d a y}^{a b s}
$$

The relative ridership thus highlights which areas are reinforced by public transport supply during different times of the day. Overall, asymmetries related to the reinforcement of supply appear. At night, there is a significant concentration of supply towards the center of the city, but there are also major reinforcement axes between the suburbs and the city center. The supply is more diffuse during the peak periods and gradually converges towards the center of the urban area between the midday, evening and night periods. Note that the peak time slots are long and asymmetrical: $2 \mathrm{~h} 10 \mathrm{~min}$ for the morning peak period and $3 \mathrm{~h} 30 \mathrm{~min}$ for the evening peak period. It remains to be seen to what extent these different reinforcements and asymmetries follow the spatial distribution of demand during the different time slots.

To give this work resonance with practitioners, it seems important to divide the territory according to usual practices. The territorial typology is based on the official division of the local authorities (OCSTAT) on the Swiss territory, then extended to the rest 
of the Greater Geneva area following intuitive appraisals (see Figure 5). It is split into four types: urban center, inner suburbs, outer suburbs and periurban. Figure 2 displays how the supply evolves during the day according to the territories. It validates the relevance of the typology, as it reveals differentiated supply curves, which indicate the number of vehicles in circulation on the network at each minute of the day. The further away from the center, the more pronounced the bus supply peaks. These fluctuations in the number of buses $n_{b u s}$ per time slot $t$ were quantitatively evaluated by a dispersion coefficient (with $\sigma$ as the standard deviation and $\mu$ as the mean number of buses over the period of time $t$ ):

$$
c_{d}=\sigma_{t}^{n b u s} / \mu_{t}^{n b u s}
$$

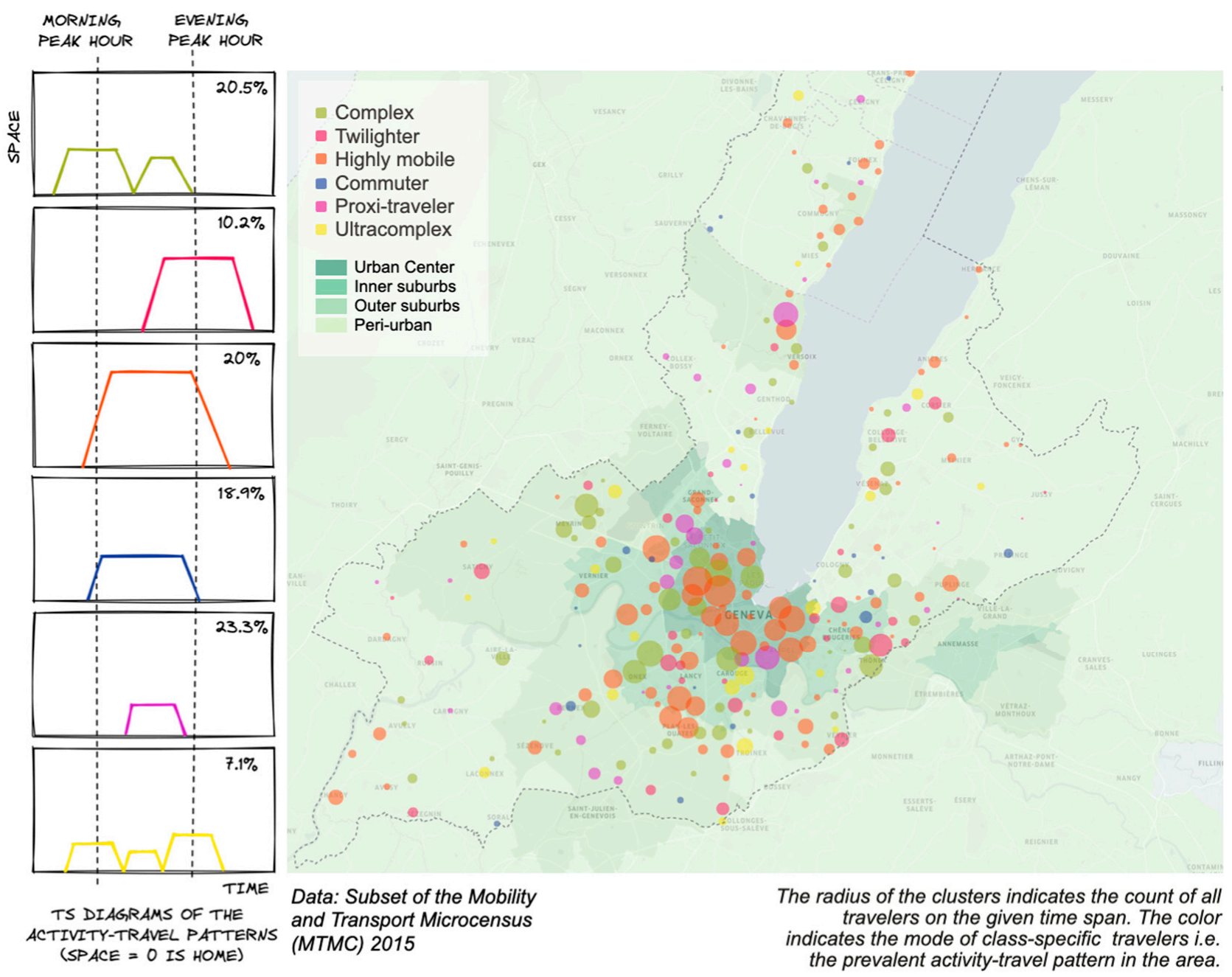

Figure 5. Spatial distribution of home locations associated to typical activity travel patterns.

The higher the coefficient of dispersion, the more the number of vehicles varies and fluctuates around the mean. Outwards, the relative variations between the two peak periods and the off-peak period become more pronounced. While a $-2 \%$ variation is calculated in the urban center between 08:00 and 12:00, the same calculation gives, respectively, $-10 \%$, $-15 \%$ and $-24 \%$ for the inner suburb, outer suburb and the periurban area. The supply is almost constant in the center throughout the day, which can satisfy any activity-travel pattern. In contrast, the supply outside the urban center fluctuates and does not seem to be able to accommodate the different activity-travel patterns identified in the previous Section 3.3. 


\subsection{Assessment of the Public Transport Supply}

The calculation of demand is based on a partial sample of all trips, which cannot be easily weighted because of the different sampling methods used in each survey. On the other hand, the GTFS data provide a comprehensive view of the vehicles on the road. A series of assumptions must therefore be made:

- The public transport supply is characterized by the bus transit only. Firstly, the rail transit supply is stable over the day (streetcars, metro and trains) and therefore has no impact on a normalized supply. Secondly, rail transit is designed for moving masses of people to major points of interests and does not tell much about how it can accommodate diverse activity-travel behaviors. Thirdly, bus coverage and ridership can be improved quickly if the ridership-coverage tradeoff is appropriate [13].

- For travel demand, all trips collected in travel surveys are considered, including active modes, public transport passengers and car drivers. The objective is not to assess solely how public transport users are served by the current supply, but also how any traveler is accommodated. Therefore, unlike the seminal work about transit desert, the research purposely put together the "choice riders" (travelers who own a car but choose to use public transport), the "captive riders" (travelers who have no other choice than using public transit) and the "potential riders" (who are not using public transit but may shift their behavior if the supply meet their needs).

- Demand and supply volumes are min-max scaled in order to be properly compared (see Equations (3) and (4), and Figure 6). This implies that the maximum bus supply is set to one. Reciprocally, the maximum class-specific demand is also set to 1 . In other words, although the demand is segmented into six classes, it is always compared to the total standardized supply. Therefore, if standardized supply and demand reach the score of 1 during the same time slot, this does not mean that every traveler has an available seat, but that class-specific demand and supply peaks are in phase.

$$
\begin{gathered}
\hat{x}_{t}^{\text {supply }}=\frac{x_{t}^{\text {supply }}-x_{\text {min }}^{\text {supply }}}{x_{\text {max }}^{\text {supply }}-x_{\text {min }}^{\text {supply }}} \\
\hat{x}_{t}^{\text {demand }}=\frac{x_{t}^{\text {demand }}-x_{\text {min }}^{\text {demand }}}{x_{\text {max }}^{\text {demand }}-x_{\text {min }}^{\text {demand }}}
\end{gathered}
$$

In this work, it is proposed to study the phase shifts and differences in amplitude between supply and demand (see Figure 7). With no accurate data regarding the total travel demand (the travel data are representative but would require a synthetic populationbased extension) and bus-specific seat capacity of the public transit supply (the bus fleet is composed of simple buses but also one- and two- articulation buses), there is no question of comparing the total supply with the total demand.

Therefore, the supply-demand coefficient of variation $C V_{t}$ is computed as the normalized distance between the reduced curves of supply and demand $C V_{t}^{0}$ at time $t$ (see Equation (5)). This method is often used in the literature to evaluate the error between measured and predicted data. A positive coefficient means an oversupply with respect to demand, and a negative one means an undersupply. 

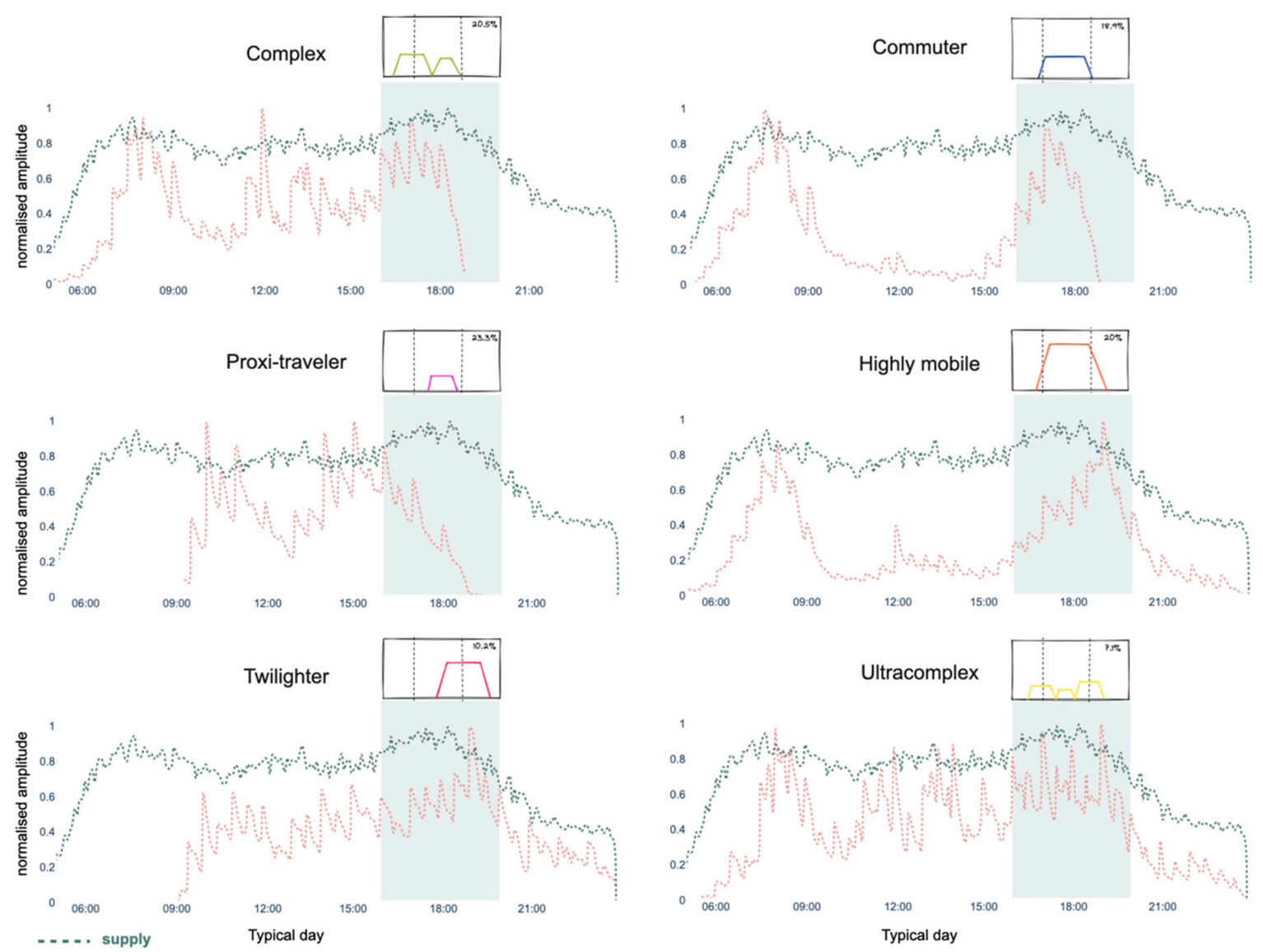

Figure 6. Standardized amplitude variations between travel demand (EDGT 2016 and MTMC 2015) and bus transit supply (GTFS 2018).

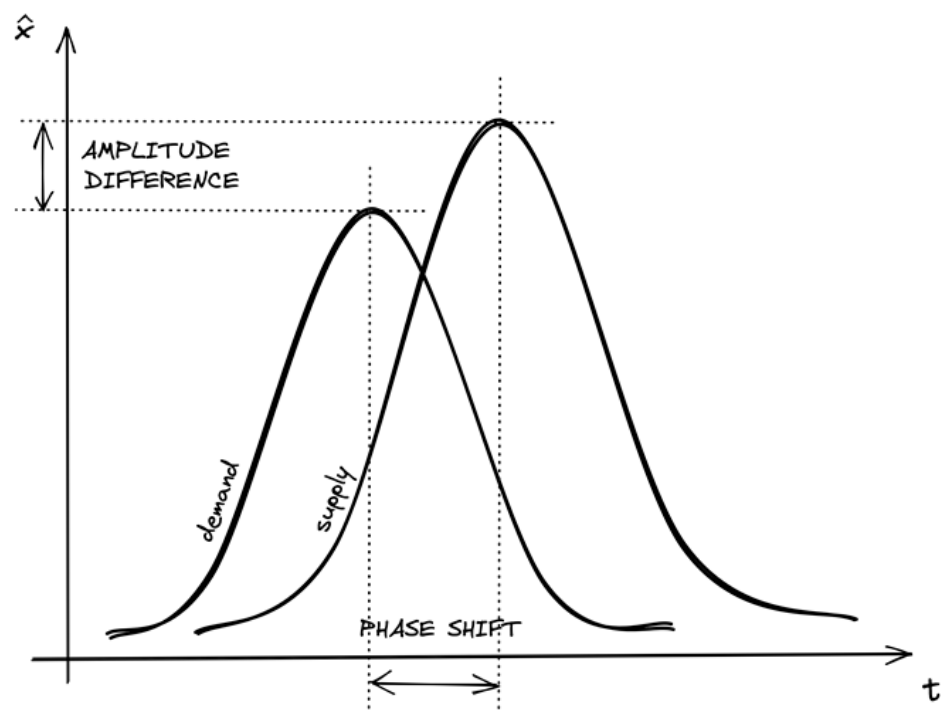

Figure 7. Two-dimension supply-demand assessment principle.

$$
C V_{t}=\frac{C V_{t}^{0}-\overline{C V^{0}}}{\sigma_{C V^{0}}}
$$

with $\overline{C V^{0}}$ the mean of the coefficient of variation, and $\sigma_{C V^{0}}$ the standard deviation. The Coefficient of Variation interpretation is as follows: 
- The threshold $C V_{t}=0$ is equivalent to a supply perfectly adjusted to the demand;

- For values of $C V_{t}>1$, there is an oversupply;

- For values of $C V_{t}<1$, there is an undersupply;

- For values $-1<C V_{t}<1$, the supply-demand gap is considered satisfactory, with $C V t^{+}$a very good supply, and $C V_{t}^{-}$a good supply.

In the context of this research, the coefficient of variation $\overline{C V_{t}}$ is averaged over the identified time slots introduced in Table 1 . Note that because of how the coefficient of variation is defined, an "oversupply" may be a rather low demand, and conversely.

\section{Results}

This section first discusses the dynamics of demand and the dynamics of supply over the course of the day. Then, the amplitude differences and phase shifts between the demand and supply curves are qualitatively examined. Finally, the public transit network is quantitatively assessed through the mapping of the supply-demand gaps with respect to time (diurnal/nocturnal, peak/off-peak), space (center, suburbs and periurban) and typical activity-travel patterns.

\subsection{Demand-Side Dynamics}

Figure 6 illustrates and maps the home locations of these typical activity-travel patterns. The vignettes on the left of the Figure show the typical, i.e., average time-space diagrams as well as their distribution in the sample. It reflects the diversity of activity programs in the Greater Geneva Area. Interestingly, if peak hours bring the network to capacity, one-third of the population build their activity-travel journey off-peak $33.5 \%$ with the Twilighter and the Proxi-traveler classes), in particular after the MPH. In addition, nearly $40 \%$ extend their activity-travels beyond the traditional EPH (including Highly Mobile, Twilighter and Ultracomplex classes).

The mapping of the home locations associated to the six typical activity-travel patterns reveals home-location preferences (qualitative assessment). Highly Mobile journeys tend to start near mass transit stations, concentrated in the urban center, along the tramway and regional train lines or near train stations. The ultracomplex journeys (activities within the proximity of home and with several home loops) tend to originate outside the urban center. The Complex and the Proxi-traveler's home location seem to be rather spread, with no specific territorial pattern. This suggests that travelers inclined to adopt different typical activity-travel patterns can be more or less impacted by transit coverage or other morphological and functional developments (see Figure 5). Home-location preferences call for further quantitative investigation regarding the residential strategies and contextual dependencies. In this direction, Figure 8 reveals the macro flow dynamics of car users.

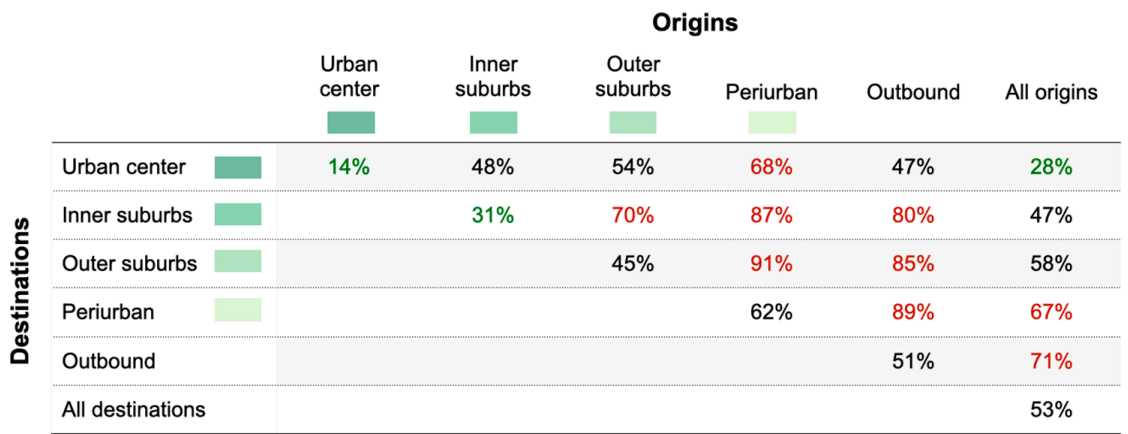

Figure 8. Share of car trips in the travel demand flows from one territory (origin) to another (destination). The aggregated share of car trips in the whole Greater Geneva Area is 53\%. This includes walk trips for distances higher than $500 \mathrm{~m}$. The Table's text color emphasizes high car use and low car use per O/D pairs-in red if more than 2 trips out of 3 are made by car, in green if less than 1 trip out of 3 . Note that the matrix is nearly symmetric $(+/-3 \%)$. 
In general, all flows inwards are either equivalent to or less than the aggregated car trip share $(53 \%)$. From all origins to the center, only $28 \%$ of trips are made by car. This is not only the result of a higher network density in the center, but also of a lower car accessibility, which leads to more congestion and poor parking conditions. The more the origin of the trips is distanced from the center, the more likely travelers are to use the car, and the inner suburb delimits a clear frontier for transit users. This result is coherent with Figure 1, that maps the network and shows that rail transit, i.e., mass transit only covers the center and inner suburbs. Although the bus network remains quite dense in the outer suburbs, the demand drops significantly, in particular for outer to inner suburbs trips.

\subsection{Supply-Side Dynamics}

A diurnal analysis of the bus supply (07:00-19:25) shows that the inner/outer suburbs concentrate most vehicles in absolute terms. However, the bus supply remains largely denser in the urban center with respect to the size of the territory. During the evening peak hour, the urban center reaches on average 43 buses spread over $16 \mathrm{~km}^{2}\left(2.7 \mathrm{buses} / \mathrm{km}^{2}\right)$, compared with 131 buses spread over $187 \mathrm{~km}^{2}$ in the outer suburbs $\left(0.7 \mathrm{buses} / \mathrm{km}^{2}\right)$. During the same period, $43 \%$ of the EPH activity occurred in the periurban area, $38 \%$ in the inner/outer suburbs and $18 \%$ in the urban center. Thus, while most of the demand is directed outward, the supply tends to remain inward. A nocturnal analysis (19:25-23:59) shows that the overall evening bus supply drops by $32 \%$ in the span of two hours (140 vehicles at 19:25 versus 95 at 21:25). Again, this drop is mainly driven by the suburbs and the periurban supply. The urban center only shows a supply decrease of $-3 \%$. This reflects a clear strategy of high center-center accessibility for nighttime travels, which are mainly leisure-oriented. Moreover, as previously noted, the morning and evening peak periods are asymmetrical in their duration, i.e., the MPH lasts two hours ten minutes and the EPH lasts three hours thirty minutes. This creates a significant discrepancy in terms of the volume of vehicle-hours deployed. The overall hourly capacity deployed at MPH (324 vh.hr) is significantly lower than in the EPH (535 vh.hr). This represents a differential of $-40 \%$, particularly marked outwards.

These time-space discrepancies confirm that demand-supply gaps do exist with respect to different activity-travel patterns. The network is actually unbalanced in time, space and volume. The rest of the section aims at understanding the extent to which the bus transit supply can accommodate the variety of activity and travel schedules and daily organizations.

\subsection{Amplitude Differences and Phase Shifts}

The existing literature introduced above stresses that transit demand does not rely on the seat capacity (i.e., available seats when onboarding buses), but rather on travelers feeling that the journey will be easy, fast and open to flexibility (i.e., number of bus vehicles serving a bus stop). In Figure 6, the demand is segmented according to the six TAT patterns. The "supply" curve corresponds the whole bus transit supply of the Greater Geneva area. Note that the patterns are clearly distinguishable on the demand curves. While in the overall demand analysis, the supply and demand curves are relatively close in shape, with characteristic peak periods, this is no longer the case for the demand segmented with typical activity-travels. Transit supply is not in phase with all activity-travel needs.

Two categories of patterns are identified. The first one travels in two to three "peaks". This is the case for the Complex, Commuter and Highly Mobile patterns, that are clearly the winners, those for whom the transit supply seems accommodating time-wise. They represent nearly $60 \%$ of the population. In sociodemographic terms, these groups are over-represented by men, who are professionally active, with a high income and a higher education degree. This means that people traveling with such patterns have the resources (in time, money, equipment) and capacities to settle where 
they have choices, i.e., where they maximize their accessibility conditions. Another two-peak pattern is the Proxi-traveler, who squeezes travels in between the two peak hours. When the Proxi-traveler demand is the highest, the transit supply hardly exceeds $80 \%$ of its capacity. This means that they do not benefit from the best ridership and coverage that the network can deploy. Proxi-travelers tend to walk more than average. They are over-represented by women, nonprofessionally active, with a lower income and a lower degree.

The second category of patterns travels quasi-continuously. This is the case of the Twilighter and Ultracomplex patterns, that solicit the network throughout their travel period. Their needs are slightly different, as they seek further flexibility and all-day travel accessibility. The ultracomplex group is over-represented by families, which implies more coupling constraints in the activity-travel scheduling, and therefore more flexibility. It raises the question of whether the "minimum service" deployed off-peak is sufficient to absorb their demand, which represents approximatively $40 \%$ of the population (including the Proxi-travelers).

Interestingly, except for Complex and Commuter patterns, most people travel right before or after the bus transit peaks. For example, the peak of affluence of Highly Mobile and Twilighter journeys is 7:00 p.m., when the supply is already in its downward curve. This analysis reveals some anomalies in the distribution of supply capacity, which could be easily rebalanced to more closely match the constraints of each TAT pattern.

\subsection{Public Transport Assessment}

The gap analysis now focuses on the relative variations in supply and demand across different territories (urban center, inner/outer suburbs and periurban). This allows us to identify which territories, which time slots and which TAT pattern are advantaged or disadvantaged by the spatio-temporal distribution of the supply. In Figure 9, the supplydemand coefficient of variation curves has been smoothed by 30 -min increments, centered and reduced. With the mapping, it is possible to highlight where and when there is a surplus and a respective shortage of supply.

The general trends of the $C V_{t}$ curves are pattern-specific. They oscillate between -1 and +1 , which indicates, respectively, an undersupply and an oversupply. For the two patterns depicted in Figure 9, the bus transit is clearly oversupplied in between peak hours whatever the territory. However, the evening peak hour shows a different result. For both patterns, the periurban area is oversupplied and the center is undersupplied. In the morning peak hour, the highly mobile coefficient of variation indicates an oversupply around 6 a.m. and drops to an undersupply before 9 a.m. This is particularly noticeable in the inner suburbs. To simplify the results, such variation will be flattened in the rest of this section, solely based on specific time slots that were introduced in Table 1, namely, the morning peak hour, the off-peak hour, the noon period, the evening peak hour and the night period.

Figure 10 summarizes the time periods, territories and typical activity-travel patterns for which, on average, supply is too abundant (green) or insufficient (red) with respect to demand. The matrix appears as a tool for a more inclusive planning of public transport. For example, it appears that Proxi-travelers are already relatively well served by the network. This is not the case for complex patterns in the evening, which are particularly affected by a lack of supply to the center, even though the demand is concentrated there. The Highly Mobile have a well-supplied network from morning to evening, because morning departures are mainly close to the center. On the other hand, their return home at night exposes them to a generalized lack of supply across the entire territory after 19:30. Note that during the morning peak hour, not all traveler groups are represented. The Proxi-traveler patterns and the Twilighters only start their travel after 9 o'clock. This leaves more room for the remaining travelers, who suffer, however, especially in the inner suburbs, from a general lack of supply. This phenomenon tends to extend outwards for Commuters and Complex travelers. On average, off-peak and noon time slots are considered to be efficient 
in the sense that all indicators are green, i.e., with a coefficient of variation between -1 and +1 . The evening peak period is often unbalanced with respect to the territories. It is considered over-supplied in the suburbs for all travelers, but also, to a lesser extent, in the inner suburbs for the Proxi-traveler type, and in the outer suburbs for the Complex type. Some negative values appear in the urban center for the Complex and Commuter types. During the night hours, the phenomenon tends to be reversed. It seems quite obvious that a transfer can be made between the excess supply in the evening peak period and the lack of supply at night. For example, by spreading out the evening peak even further in favor of night-time mobility.

undersupplied $-1<\overline{\mathrm{CV}}_{\mathrm{t}}$

fairly supplied $-1<\overline{\mathrm{CV}}_{\mathrm{t}}<0$

fairly supplied $0<\overline{\mathrm{CV}}_{\mathrm{t}}<1$

oversupplied $\quad \overline{\mathrm{CV}}_{\mathrm{t}}>1$

\section{Urban Center Inner suburbs Outer suburbs} Periurban

note: on the map, the color of the dots is based on the averaged score over the selected time span (here Evening Peak Hour)
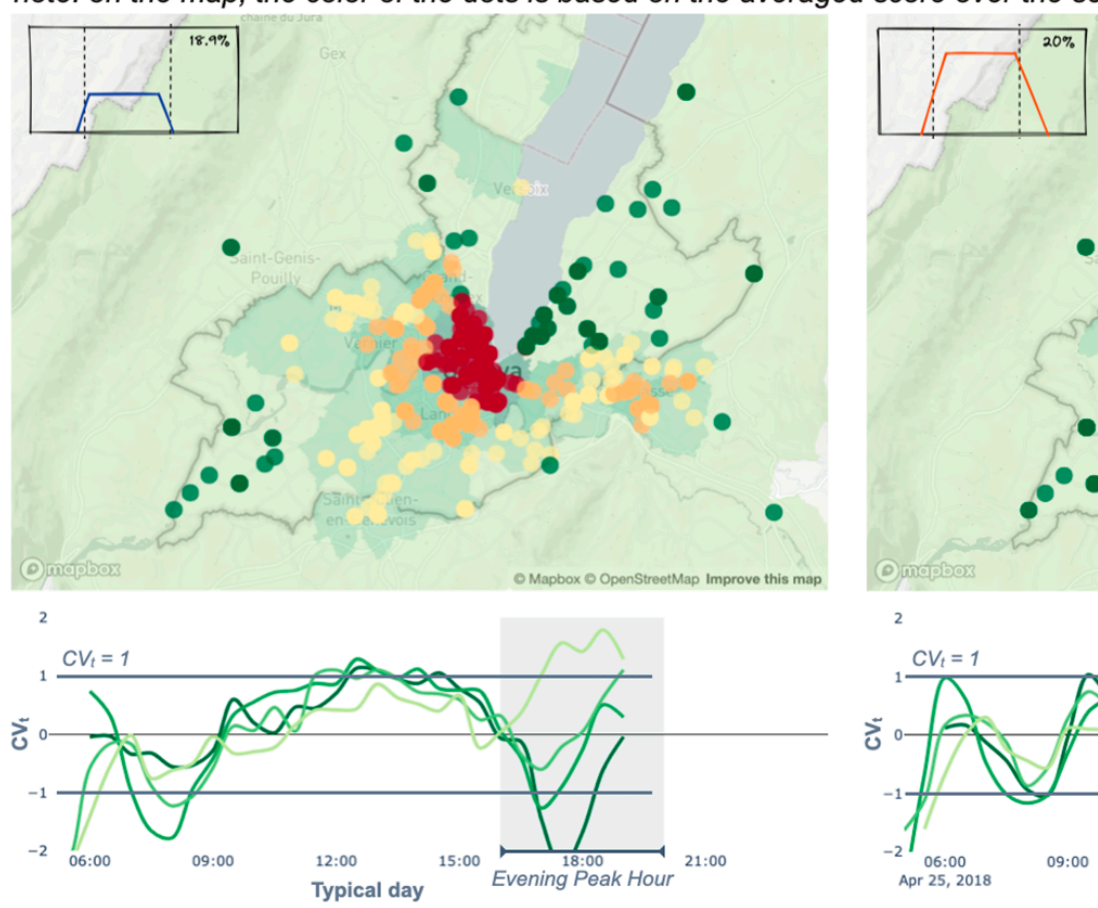

Commuter
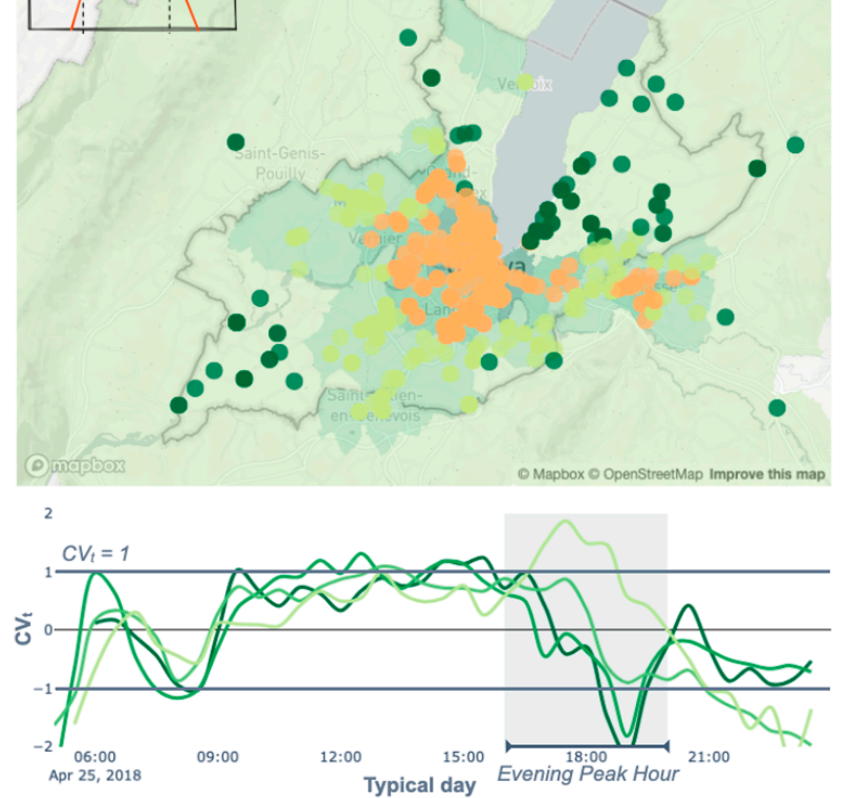

Highly mobile

Figure 9. Representations of the indicator of supply-demand variation by territory and activity-travel patterns. Each dot is a bus stop color-scaled according to the supply-demand score over a specific time slot (here the evening peak hour). Below, the green curves refer to the territorial typology, respectively the urban center, inner suburbs, outer suburbs and periurban. 


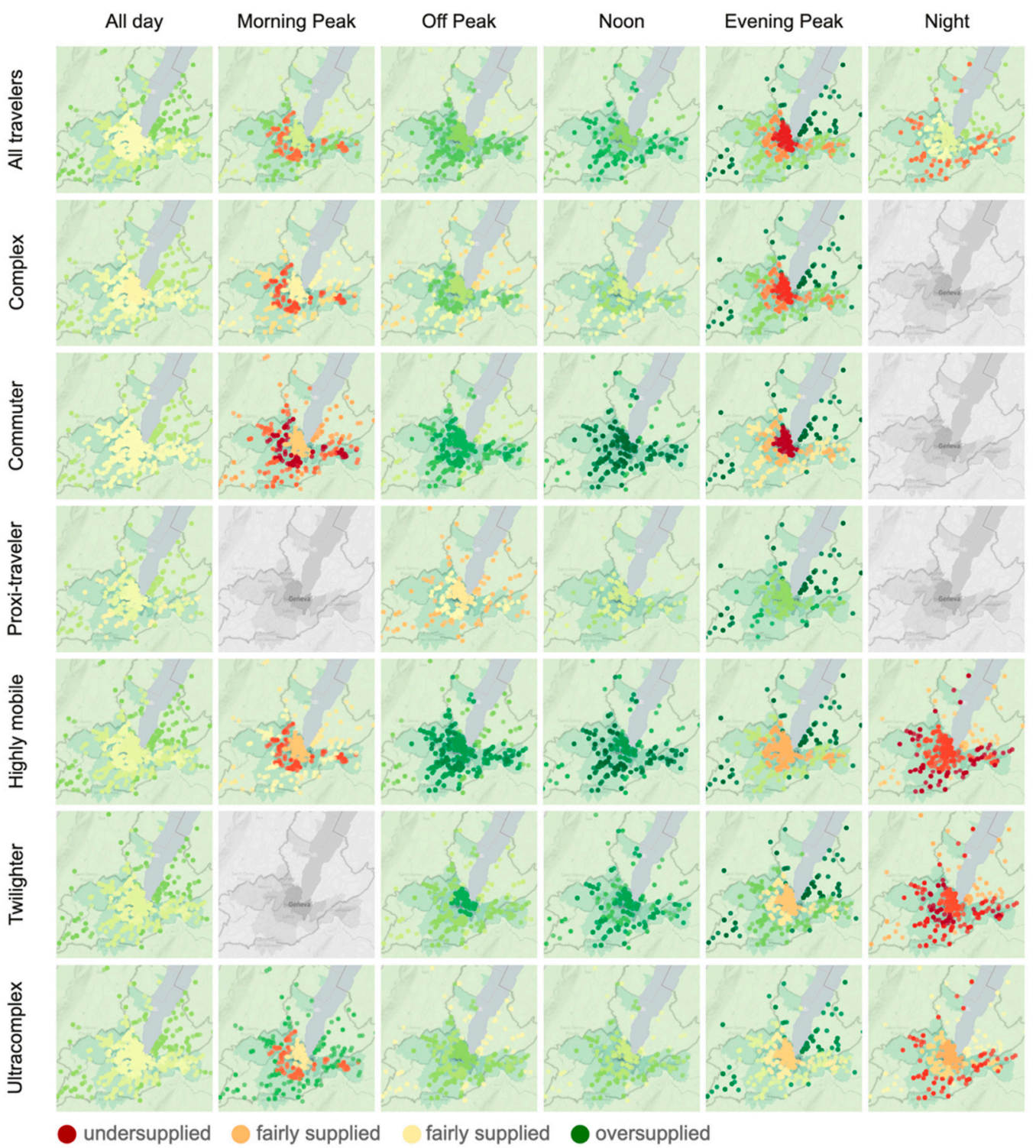

Figure 10. Matrix of demand-supply gaps in the public transport system of the Greater Geneva Area, per time slots, territories and activity-travel patterns.

\section{Discussion}

As highlighted in the literature review (see Section 2), several components have a direct implication on the quality of the public transit, including the land use, the transport system and the temporal and individual components. This paper introduces a theoreticallyinformed framework to further explore the temporal, territorial and individual aspects of transit, that are often overlooked in practice.

The temporal component is traditionally reduced to the comparison between off-peak and peak hours. The results presented in this paper show that the hegemony of peak hours must be treated with attention, and that one third of the population travels off-peak. This shows the need to redefine the indicators of public transport supply in a dynamic way. For example, the findings presented above show that supply is reinforced outwards during $\mathrm{MPH}$ and $\mathrm{EPH}$, with asymmetries between morning and evening. The supply is reinforced inwards (center and suburbs) around the peak hours. This reveals the strong entanglement between temporal and territorial dimensions in travel demand. The main take-away (as highlighted on Figure 10) is that the network can be oversupplied and undersupplied at the same time in different parts of the territory. These findings suggest that a rebalancing 
of supply in the urban area could more effectively meet travel demand without additional financial support.

The individual component shows that the demand is heterogeneous in terms of activity-travel patterns. The classification of typical activity-travel patterns is particularly suitable for analyzing demand-supply gaps. When aggregated, the demand is driven by commuters and highly mobile persons, who are overrepresented (almost $40 \%$ of the population) and travel almost exclusively during the peak hours. The six activity-travel schemes are characterized by the complexity of the daily activity schedule, the travelers' temporal constraints and the time-space dispersion of the activity space. The typical activity-travel patterns are purposely established independently of the geographic context, socioeconomic categories and modal preferences. The higher the complexity, the more the routing of the public transport journey is critical (in terms of public transport chaining and transferring). The temporal constraints participate in the effect induced by peak-hour, and the more dispersed the activity-travel patterns, the more flexible the supply must be (i.e., moving toward a cadenced schedule). When clustering demand into these six groups (Complex, Twilighter, Highly Mobile, Commuter, Proxi-traveler, Ultracomplex), the class-specific demand-supply gap analysis shows winners and losers. Furthermore, the socio-demographics show an uneven distribution of gender, and a familial composition or modal practices. Future work may add the additional layer of "transit captivity" to the individual component for differentiating discretionary riders, potential riders and transit dependents. Nevertheless, even for those profiles that do not follow mass travel schedules (i.e., peak hours), the network certainly offers sufficient capacity to absorb all demand in practical terms. Indeed, a minimum service is provided throughout the day. The characterization of this "minimum service" is an interesting subject for further work to feed the ridership and coverage debate.

Beyond a functional assessment of supply, and a fortiori, of accessibility, this research reveals that populations with complex activity patterns as well as populations out of phase with rush hours are disadvantaged. This implies issues of inclusiveness, and in particular gender issues. In fact, the benefits induced by public transport to the city and to the society are manifold. Yet, many of the benefits tend to be overlooked, while transit costs are marginal when the transit service is fairly used [9]. Public transit may even constitute the only durable alternative to tackle urban space saturation, global urbanization, population aging and population growth. In this work, the demand-supply gap evaluation is twofold. Firstly, a qualitative analysis of the standardized curves of supply and demand allow us to identify the temporal shifts and differences in amplitudes. In traffic engineering, the transit network is traditionally designed for peak-hours, when the network reaches capacity. It appears important, however, to maintain a fairly capacitated network for others, who travel off-peak. Secondly, a quantitative assessment of the transit adequacy per territory and time slots allows for the identification of where, when and for whom the supply and demand mismatch, i.e., where, when and for whom the public transport is oversupplied or undersupplied.

\section{Conclusions}

Focusing on bus transit rather than the entire public transit network means focusing on what is flexible and adaptable in the system. On the one hand, bus transit can easily evolve with travel demand, with the development of the city and with the transformations brought about by mobility-as-a-service. On the other hand, rail transport (subways, streetcars, regional trains, etc.) is comparatively static, as it remains unchanged for decades. With high ridership, rail transit implies an oversupply in the network. This induces a high potential for passenger appropriation (trains and streetcars passing at fixed times and/or with small headways), but also a very limited coverage. The idea that "buses can be improved quickly" [2] (p. 9), both in terms of coverage and ridership, supports the research principle of focusing exclusively on bus transit supply when it comes to assessing the demand-supply gaps. 
As argued and supported throughout this paper, the approach to public transport planning today is based primarily on land-use and transport system components; and the system capacity is generally sized on aggregated daily passenger volumes. However, the current state of the art calls for further integration of temporal and individual components, since fast, frequent and porous transit networks are driving the attractiveness of public transport from a functional and practical perspective. Activity-chaining is barely considered, and insufficient efforts are made to allow people to build their lives around the public transit system, and in particular bus transit [2] (p. 24).

Without being necessarily exhaustive, the assessment of the transit network must therefore encompass social, spatial and temporal components in addition to the transport system characteristics. The approach presented in this paper allows for a finer appreciation of the gaps between transit supply and travel demand, and a more refined approach to the quality of public transport services in order to take into account the possibilities of the linkages that individuals face in their daily lives. This goes beyond the current practice, where most of the indicators of supply are accessibility-based, and where indicators of demand remain straightforward (e.g., volume of trips). The spatial dimension and transportation characteristics have been widely studied. However, the temporal component and individual component were barely investigated.

While cities need to address the competing challenges of population growth, sustainability and inclusivity, public transports are inevitably part of the solution. This paper is a contribution for a better harmonization of demand and supply.

Funding: This research was co-funded by the Canton of Geneva, and ENAC Cluster Grant 2020.

Institutional Review Board Statement: Not applicable.

Informed Consent Statement: Informed consent was obtained from all subjects involved in the study by the Swiss Federal Office for Spatial Development and Federal Office of Statistics. The data is made freely accessible under a non-disclosure agreement for research purposes.

Data Availability Statement: The transit supply data (GTFS data) can be found at https:/ / opentransportdata. swiss / (accessed on 28 November 2021), as open data. The demand data (microcensus data) are available for research purposes upon request at the Federal Office for Statistics, Switzerland.

Acknowledgments: Thanks to Alexis Gumy for the discussions and inspiration. This research was initiated and partially supported by the Canton de Genève, Switzerland.

Conflicts of Interest: The author declares no conflict of interest.

\section{References}

1. NACTO (National Association of City Transportation Officials). Transit Street Design Guide. 2016. Available online: https: //nacto.org/publication/transit-street-design-guide/ (accessed on 13 December 2021).

2. Higashide, S. Better Buses, Better Cities: How to Plan, Run, and Win the Fight for Effective Transit; Island Press: Washington, DC, USA, 2019.

3. Sulis, P.; Manley, E.; Zhong, C.; Batty, M. Using mobility data as proxy for measuring urban vitality. J. Spat. Inf. Sci. 2018, 2018, 137-162. [CrossRef]

4. Mezoued, A. L'in-adhérence spatiale du tramway d'Alger à l'échelle locale. In Dynamiques Urbaines à Alger: La (re) Fabrication de la Ville en Questions; L'Harmattan: Paris, France, 2016; pp. 247-265.

5. Mezoued, A.M.; Letesson, Q.; Kaufmann, V. Making the slow metropolis by designing walkability: A methodology for the evaluation of public space design and prioritizing pedestrian mobility. Urban Research and Practice 2021. [CrossRef]

6. TDM (Transportation Demand Management). Public Transit Encouragement; TDM Encyclopedia Victoria Transport Policy Institute: Victoria, BC, Canada, 2019; Available online: https:/ /www.vtpi.org/tdm/tdm112.htm (accessed on 13 December 2021).

7. Hale, C.A. New approaches to strategic urban transport assessment. Aust. Plan. 2011, 48, 173-182. [CrossRef]

8. Geurs, K.T.; van Wee, B. Accessibility evaluation of land-use and transport strategies: Review and research directions. J. Transp. Geogr. 2004, 12, 127-140. [CrossRef]

9. Litman, T. Evaluating Public Transit Benefits and Costs; Victoria Transport Policy Institute: Victoria, BC, Canada, 2021.

10. Bhat, C.R.; Guo, J.Y.; Sen, S.; Weston, L. Measuring Access to Public Transportation Services: Review of Customer-Oriented Transit Performance Measures and Methods of Transit Submarket Identification. 2005. Available online: https://trid.trb.org/ view / 859415 (accessed on 15 December 2021). 
11. Marsden, G.; Bonsall, P. Performance targets in transport policy. Transp. Policy 2006, 13, 191-203. [CrossRef]

12. Stradling, S.; Carreno, M.; Rye, T.; Noble, A. Passenger perceptions and the ideal urban bus journey experience. Transp. Policy 2007, 14, 283-292. [CrossRef]

13. Walker, J. Purpose-driven public transport: Creating a clear conversation about public transport goals. J. Transp. Geogr. 2008, 16, 436-442. [CrossRef]

14. Chen, X. Review of the Transit Accessibility Concept: A Case Study of Richmond, Virginia. Sustainability 2018, 10, 4857. [CrossRef]

15. van Acker, V.; van Wee, B.; Witlox, F. When Transport Geography Meets Social Psychology: Toward a Conceptual Model of Travel Behaviour. Transp. Rev. 2010, 30, 219-240. [CrossRef]

16. Schneider, C.M.; Belik, V.; Couronné, T.; Smoreda, Z.; González, M.C. Unravelling daily human mobility motifs. J. R. Soc. Interface 2013, 10, 20130246. [CrossRef]

17. Liu, Z.; Yu, J.; Xiong, W.; Lu, J.; Yang, J.; Wang, Q. Using mobile phone data to explore spatial-temporal evolution of homebased daily mobility patterns in Shanghai. In Proceedings of the 2016 International Conference on Behavioral, Economic and Socio-cultural Computing (BESC), Durham, NC, USA, 11-13 November 2016; pp. 1-6. [CrossRef]

18. Jiang, S.; Ferreira, J.; Gonzalez, M.C. Activity-Based Human Mobility Patterns Inferred from Mobile Phone Data: A Case Study of Singapore. IEEE Trans. Big Data 2017, 3, 208-219. [CrossRef]

19. Lei, D.; Chen, X.; Cheng, L.; Zhang, L.; Ukkusuri, S.V.; Witlox, F. Inferring temporal motifs for travel pattern analysis using large scale smart card data. Transp. Res. Part C Emerg. Technol. 2020, 120, 102810. [CrossRef]

20. Su, R.; McBride, E.C.; Goulias, K.G. Unveiling daily activity pattern differences between telecommuters and commuters using human mobility motifs and sequence analysis. Transp. Res. Part A Policy Pract. 2021, 147, 106-132. [CrossRef]

21. Reades, J.; Calabrese, F.; Sevtsuk, A.; Ratti, C. Cellular Census: Explorations in Urban Data Collection. IEEE Pervasive Comput. 2007, 6, 30-38. [CrossRef]

22. Ahas, R.; Aasa, A.; Silm, S.; Tiru, M. Daily rhythms of suburban commuters' movements in the Tallinn metropolitan area: Case study with mobile positioning data. Transp. Res. Part C Emerg. Technol. 2010, 18, 45-54. [CrossRef]

23. Shen, J.; Cheng, T. A framework for identifying activity groups from individual space-time profiles. Int. J. Geogr. Inf. Sci. 2016, 30, 1785-1805. [CrossRef]

24. Drevon, G.; Gumy, A. Understanding multimodality through rhythm of life: Empirical evidence from the Swiss case study. In Handbook of Urban Mobilities; Routledge: London, UK, 2020.

25. Jiao, J.; Dillivan, M. Ball State University Transit Deserts: The Gap between Demand and Supply. J. Public Transp. 2013, 16, 23-39. [CrossRef]

26. Stanley, J.; Lucas, K. Social exclusion: What can public transport offer? Res. Transp. Econ. 2008, 22, 36-40. [CrossRef]

27. Wu, B.M.; Hine, J.P. A PTAL approach to measuring changes in bus service accessibility. Transp. Policy 2003, 10, 307-320. [CrossRef]

28. Benenson, I.; Ben-Elia, E.; Rofé, Y.; Geyzersky, D. The benefits of a high-resolution analysis of transit accessibility. Int. J. Geogr. Inf. Sci. 2017, 31, 213-236. [CrossRef]

29. Ambarwati, L.; Verhaeghe, R.; van Arem, B.; Pel, A.J. Assessment of transport performance index for urban transport development strategies-Incorporating residents' preferences. Environ. Impact Assess. Rev. 2017, 63, 107-115. [CrossRef]

30. Yang, R.; Liu, Y.; Gan, W. Comprehensive Public Transport Service Accessibility Index-A New Approach Based on Degree Centrality and Gravity Model. Sustainability 2019, 11, 5634. [CrossRef]

31. Peungnumsai, A.; Miyazaki, H.; Witayangkurn, A.; Kim, S. A Grid-Based Spatial Analysis for Detecting Supply-Demand Gaps of Public Transports: A Case Study of the Bangkok Metropolitan Region. Sustainability 2020, 12, 10382. [CrossRef]

32. Currie, G. Quantifying spatial gaps in public transport supply based on social needs. J. Transp. Geogr. 2010, 18, 31-41. [CrossRef]

33. Fransen, K.; Neutens, T.; Farber, S.; de Maeyer, P.; Deruyter, G.; Witlox, F. Identifying public transport gaps using time-dependent accessibility levels. J. Transp. Geogr. 2015, 48, 176-187. [CrossRef]

34. Kaeoruean, K.; Phithakkitnukoon, S.; Demissie, M.G.; Kattan, L.; Ratti, C. Analysis of demand-supply gaps in public transit systems based on census and GTFS data: A case study of Calgary, Canada. Public Transp. 2020, 12, 483-516. [CrossRef]

35. Liao, Y.; Gil, J.; Pereira, R.H.M.; Yeh, S.; Verendel, V. Disparities in travel times between car and transit: Spatiotemporal patterns in cities. Sci. Rep. 2020, 10, 4056. [CrossRef]

36. He, S.Y. Does flexitime affect choice of departure time for morning home-based commuting trips? Evidence from two regions in California. Transp. Policy 2013, 25, 210-221. [CrossRef]

37. Saleh, W.; Farrell, S. Implications of congestion charging for departure time choice: Work and non-work schedule flexibility. Transp. Res. Part A Policy Pract. 2005, 39, 773-791. [CrossRef]

38. Google Transit API. GTFS Documentation. 2020. Available online: https://developers.google.com/transit/gtfs/reference (accessed on 13 December 2021).

39. Toso, S. Library GTFS Functions. 2020. Available online: https://github.com/Bondify/gtfs_functions (accessed on 28 November 2021).

40. CxAalto. Library Gtfspy. 2020. Available online: https://github.com/CxAalto/gtfspy (accessed on 28 November 2021).

41. Butts, K. Library Peartree. 2021. Available online: https://github.com/kuanb/peartree (accessed on 28 November 2021). 